\title{
PHOTOGRAMMETRIC DEFORMATION MONITORING OF THE SECOND BOSPHORUS BRIDGE IN ISTANBUL
}

\author{
Özgür AVŞAR ${ }^{a, b, c}$, Devrim AKCA ${ }^{b}$, Orhan ALTAN $^{a}$ \\ ${ }^{a}$ Department of Geomatics, Istanbul Technical University, Istanbul - (avsarem, oaltan)@itu.edu.tr \\ ${ }^{\mathrm{b}}$ Department of Civil Engineering, Isik University, Istanbul - akca@isikun.edu.tr \\ ${ }^{\mathrm{c}}$ Ekinoks Surveying Software Engineering Ltd. Co., Istanbul
}

Commission V, WG

KEY WORDS: Monitoring, Deformation, Photogrammetry, Bridge

\begin{abstract}
:
Improving the efficiency of bridge inspection and minimizing the impact of dynamic load on the long term deterioration of the bridge structure reduces maintenance and upkeep costs whilst also improving bridge longevity and safety. This paper presents the results of an on-going project whose ultimate goal is the real-time photogrammetric monitoring the structural deformations of the second Bosphorus Bridge of Istanbul.
\end{abstract}

\section{INTRODUCTION}

Bridges are exposed to intensive and dynamic loads, unsteady weather conditions, material fatigue and aging process. All these factors cause deformations on the construction parts. The importance of the monitoring and early identifying the bridge deformations is essential once the maintenance, repair and even the reconstruction costs are considered.

Monitoring campaigns of long bridges are becoming more and more common as the research fields of structural health monitoring and performance monitoring grow.

A very first photogrammetric bridge monitoring project, including a condition survey and vertical deflection measurement, was carried out by Bales and Hilton in 1985. The bridge has a 3-span continuous structure with a total length of $139 \mathrm{~m}$. The length of the center span was measured as $51 \mathrm{~m}$. The camera was positioned at three locations under mid-span facing up at a distance of about $10.8 \mathrm{~m}$. The average difference between photogrammetric measurements and level readings was approximately $3 \mathrm{~mm}$ (Bales and Hilton, 1985).

Kim (1989) performed a long-term deformation monitoring of a $526 \mathrm{~m}$ long highway bridge using photogrammetry. The project utilized a camera with a $150 \mathrm{~mm}$ lens. The distance between the bridge and the camera was $122 \mathrm{~m}$. Images were recorded on conventional $230 \times 230 \mathrm{~mm}$ film and were analyzed using a program developed specifically for the project. It was concluded that the precision of the deformation measurement using photogrammetry was within $\pm 14 \mathrm{~mm}$ in the length and height directions, and $\pm 30 \mathrm{~mm}$ in the width direction (Kim, 1989).

Leitch (2002) and Jauregui et al. (2003) conducted a comprehensive study on bridge deflection measurement using close-range photogrammetry. Studies were performed on a laboratory steel beam and on two field bridges. The first bridge tested was a single-span, prestressed concrete bridge with a length of $32.2 \mathrm{~m}$. The second was a simple-supported steel girder bridge, under truck loading and having 7-spans. In the experiments of the first bridge, photogrammetric measurements of the initial camber were compared with level rod readings. The maximum deviation of the two measurements was within $\pm 17 \mathrm{~mm}$ for four of the girders, and $28 \mathrm{~mm}$ for the remaining girder (Leitch, 2002). For the second experiment; the photogrammetric measurement results were compared with those obtained from finite element analysis, level rod readings, and curvature-based measurements derived from strain gages. The maximum deflection was about $8 \mathrm{~mm}$. The differences in deflection measurements from photogrammetry, curvature, and the level rod were within $0.5-1.5 \mathrm{~mm}$ for all girders at the midspan (Jauregui et al., 2003).

Zogg and Ingensand present a deformation monitoring application with Terrestrial Laser Scanning for an $1116 \mathrm{~m}$ length viaduct and verified their results with precise leveling (Zogg and Ingensand, 2008).

Koo and et al. (2010; 2013) presents a structural health monitoring system using an automated Total Positioning System and its application to a 3-span suspension bridge. Fifteen reflectors were installed on the bridge deck, on top and wall of towers and on top of side towers, monitored for a period of three months to measure the longitudinal, vertical and lateral movements of the bridge (Koo and et al., 2010; 2013).

This paper presents the results of an on-going project whose ultimate goal is the real-time photogrammetric monitoring the structural deformations of the second Bosphorus Bridge. The final aim of the project is to design and to realize an operational and on-line photogrammetric monitoring system for deformation measurements of the bridge. The project is a collaborative work of Istanbul Technical University and the General Directorate of Highways of Turkey.

The first 150 meters of the bridge body is planned to monitor using the photogrammetric technique. This is a pilot project which is going to be extended to monitor the entire bridge, if the reasonable results are achieved. 
In the next section the second Bosphorus Bridge is introduced. The third section addresses the network design work in which the stations, targets, cameras and lenses are interactively defined.. The fourth and fifth sections summarize the result of the calibration step and in-door test, respectively. The project realization is explained in the sixth section. The computational results are discussed in the last section.

\section{THE SECOND BOSPHORUS BRIDGE}

Istanbul has two suspension bridges which link the European and Asian parts of Istanbul and of Turkey.

The second one, the Fatih Sultan Mehmet Bridge, is a modern type of suspension bridge (Figure 1). It is the $19^{\text {th }}$ longest suspension bridge of the world. It started the public use in 1988. An immense level of transportation load comes to this bridge, since it lies on the "arteries" of the Turkish transportation net. The daily traffic of the bridge is approximately 180.000 vehicles. It spans 1510 meters from bank to bank. The distance between the two pairs of suspension towers is 1090 meters and towers are 105 meters above the roadway. The distance from the roadway carrier (lower edge) to the sea level is 64 meters (Apaydın and Erdik, 2001; Apaydın 2002).

After the earthquake occurred on $17^{\text {th }}$ of August 1999, condition of the bridges became an important issue due to their major importance for the transportation. In connection, a seismic analysis project was implemented by the General Directorate of Highways. As a part of this project; a GPS monitoring campaign was held in July 2001. GPS observations with 0.1 seconds epoch interval were recorded for the same days of consecutive weeks. In addition, ancillary data such as traffic volume and weather conditions of the corresponding observation period were collected. The time series of the respective point displacements (deformations) were linked to the ancillary data. Then, in-depth analysis and comparison of the individual observation days was carried out. As the result of the study, a maximum of $40 \mathrm{~mm}$ height displacement within 13 seconds of periods was observed (Aky1lmaz et al., 2004).

On the other hand, reinforcement activities of the bridge components are periodically performed by the General Directorate of Highways. The last two studies were carried out in 2009 and 2013.

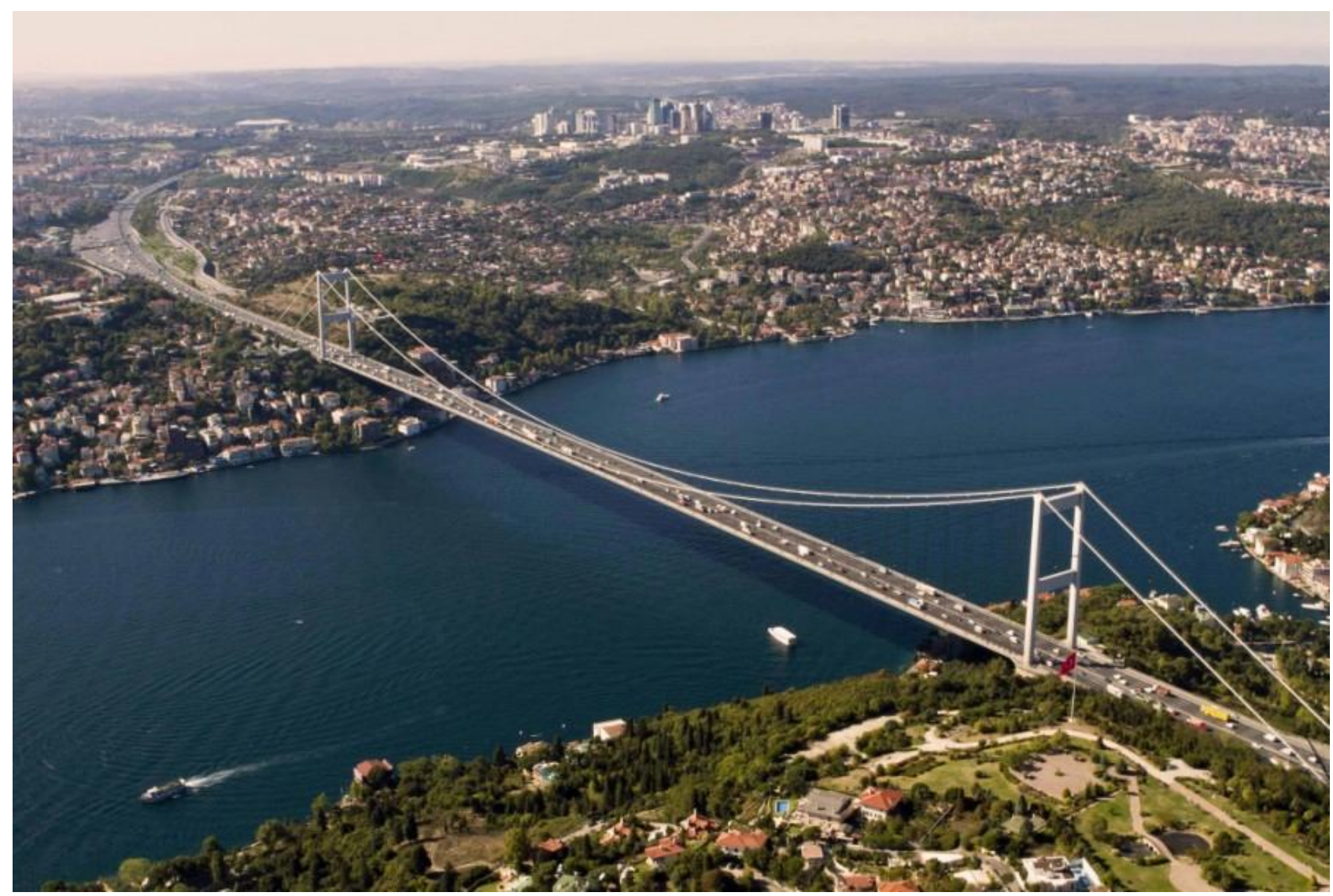

Figure 1. The second Bosphorus Bridge in Istanbul

\section{NETWORK DESIGN}

An area just in front of the suspension towers of the European side is identified for the equipment installation. A reconnaissance fieldwork was performed to determine the feasible monitoring stations and targets. An initial map of the area was generated using the total station measurements. This information served as input to a photogrammetric network simulation work. The task is to estimate the a posteriori point positioning precision provided that the input parameters of the designed photogrammetric network are given. The proper camera locations, formats and lenses were interactively examined in the simulated environments. The network design and simulation steps are essentially required in order to predict the theoretical precisions of point coordinates (Amiri Parian et al., 2007). 
Accordingly, 4 megapixel Basler A402 video cameras (Basler AG, Germany) were chosen for the image acquisition. Technical details of the cameras are given in Table 1.

Three-camera based convergent multi-image acquisition geometry was adopted to provide adequate photogrammetric coverage of the experiment area. The a priori point positioning precision of the signalized targets was estimated to be \pm 46.0 $\mathrm{mm}, \pm 26.9 \mathrm{~mm}$ and $\pm 2.5 \mathrm{~mm}$ along the $\mathrm{X}, \mathrm{Y}$ and $\mathrm{Z}$ directions respectively (Figure 2). The a priori standard deviation of the image point observations was assumed to be \pm 0.1 pixel. The design consideration for the project is to track the signalized points within a positional accuracy of \pm 5 to $6 \mathrm{~cm}$.

\begin{tabular}{ll}
\hline & Basler A402 \\
\hline Sensor type & CMOS \\
Sensor size & $1 / 4$ inches \\
Image format & $2352 \times 1726$ pixels \\
Frame rate & 24 fps \\
Pixel pitch & 7 microns \\
Data transmission & Camera Link \\
protocol & Carl Zeiss SLR Distagon $\mathrm{T}^{*}$ \\
Lens & $3.5 / 18$ \\
& F-mount \\
\hline
\end{tabular}

Table 1: Technical details of Basler A402 video camera

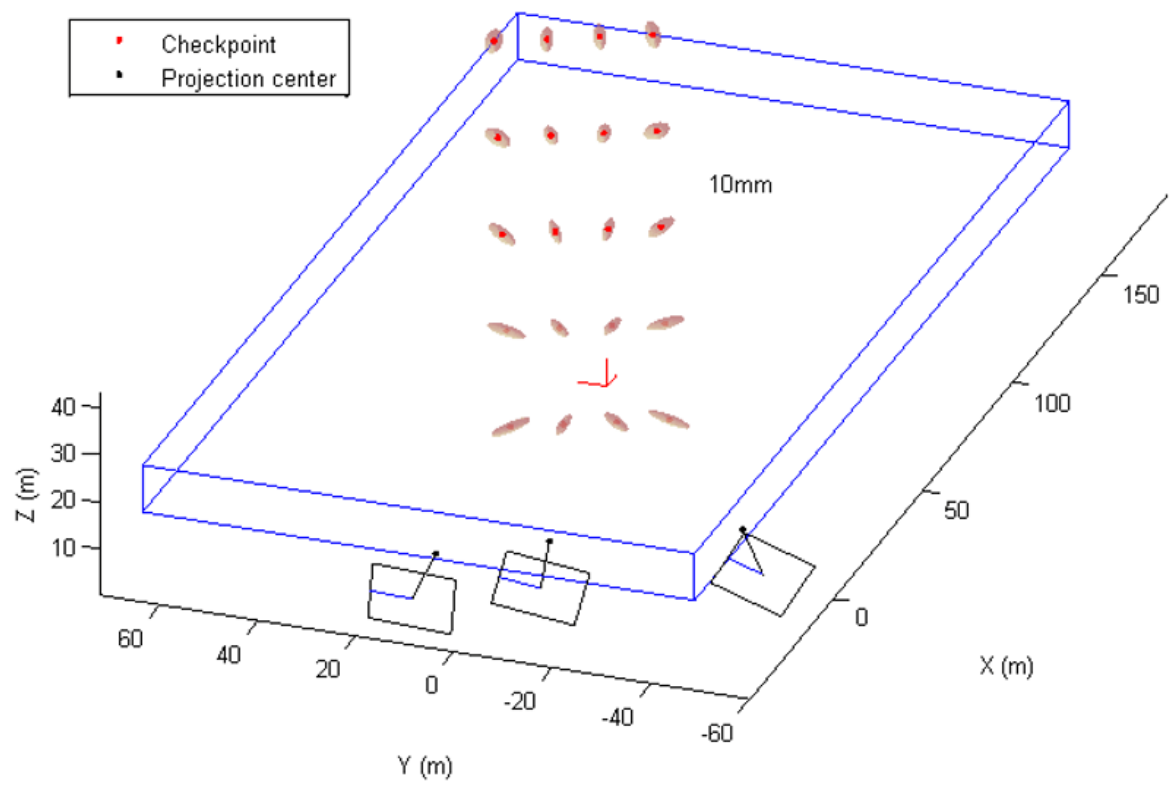

Figure 2. The a priori estimated error ellipsoids of some representative signalized points attached below of the bridge body

\section{CAMERA CALIBRATION}

Photogrammetry deals with precise measurements from images Thus; accurate calibration of the imaging sensors is one of the major goals. The geometrical model of the image acquisition process is a perspective projection. The bundle method associates the adjustment of the image measurements and the estimation of the camera parameters. The bundle method is considered the most flexible, general, and accurate sensor model, widely used in close-range applications (Remondino, 2004). The calibration of the cameras has been carried out by using the test field established at the Institute of Geodesy and Photogrammetry at ETH Zurich (Akca and Gruen, 2009; Akca, 2013). The results of the camera calibration computation are given in Table 2.

\begin{tabular}{ccrrrrr}
\hline & \multicolumn{2}{c}{ Camera 1 } & \multicolumn{2}{c}{ Camera 2 } & \multicolumn{2}{c}{ Camera 3 } \\
\hline $\mathrm{c}(\mathrm{mm})$ & 18.600 & \pm 0.0004 & 18.583 & \pm 0.0004 & 18.595 & \pm 0.0004 \\
$\mathrm{x} 0(\mathrm{~mm})$ & 0.1426 & \pm 0.0008 & 0.1000 & \pm 0.0008 & 0.0741 & \pm 0.0007 \\
$\mathrm{y} 0(\mathrm{~mm})$ & 0.1977 & \pm 0.0006 & -0.1414 & \pm 0.0006 & 0.1357 & \pm 0.0006 \\
\hline
\end{tabular}

Table 1: Camera calibration results

\section{IN-DOOR TEST}

A Matlab program has been developed for image acquisition and storage. This in-house developed program enables the three cameras to shoot (and store) the frames simultaneously by starting the capturing process of all cameras at the same time with using the parallel processing advantage of Matlab pools. An average synchronization error of \pm 8 milliseconds is achieved in the preliminary tests.

Additional in-door tests were performed using a pendulum setup (Figure 3 ) which was established at the photogrammetry laboratory of the Geomatics Engineering Department of Istanbul Technical University (ITU). The oscillation of the pendulum was monitored by the three cameras with an image acquisition frequency of $24 \mathrm{fps}$. Only an area of interest of 1200 $\mathrm{x} 880$ pixels over the full image format is recorded thanks to the windowing capability of the CMOS sensor. The in-door pendulum test gave us useful information about the synchronization error and the point positioning error prior to the out-door tests. 


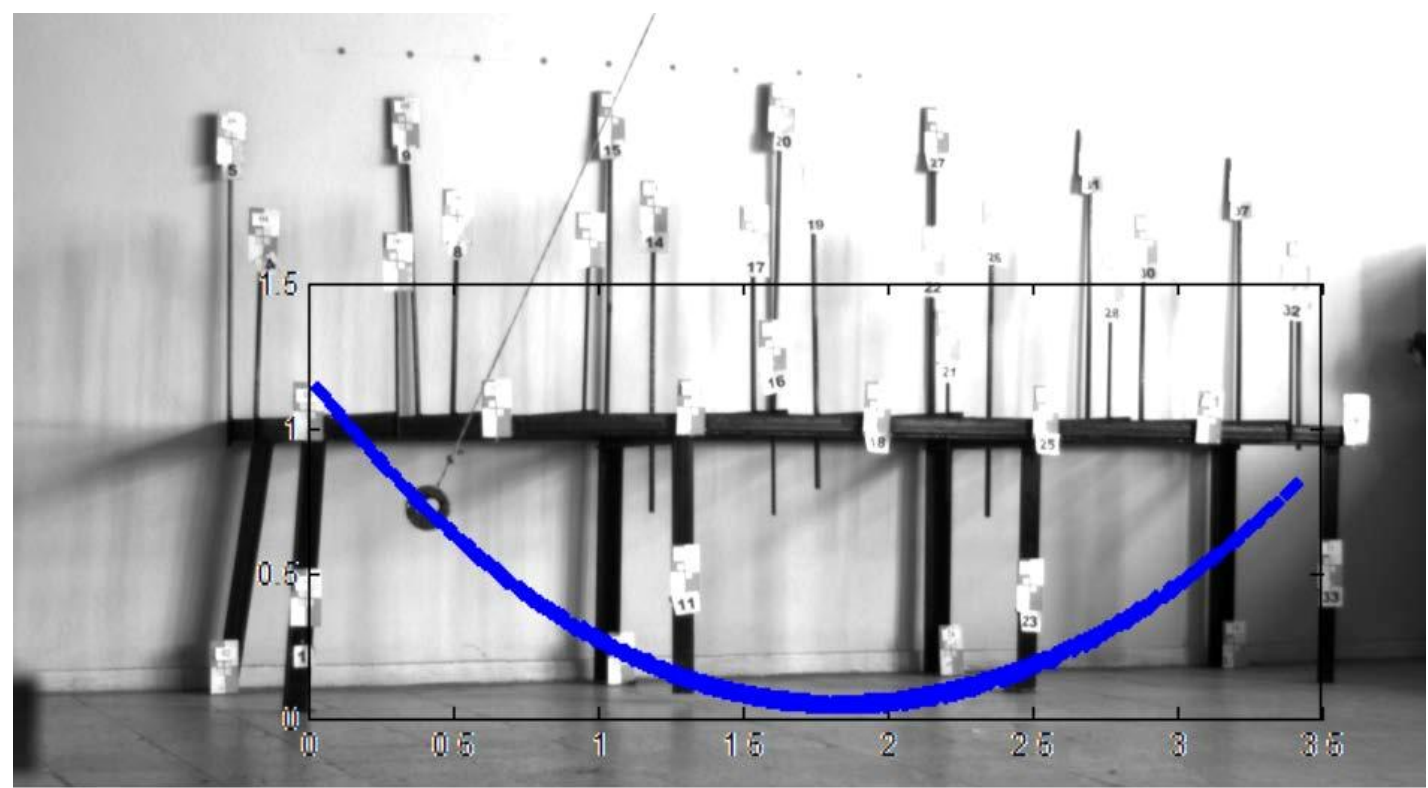

Figure 3. The pendulum setup

\section{PHOTOGRAMMETRIC MEASUREMENT}

Four pillars out of three for the cameras and the remaining one for an image assisted total station were constructed at the field. The total station simultaneously collected the geodetic measurements which were used as validation data later. The $\mathrm{X}$, $\mathrm{Y}$ and $\mathrm{Z}$ coordinates of the pillars were measured with static GPS observations. A part of the field constellation is shown in Figure 4.

A total number of 12 LEDs, equipped with 12 volt accumulator for the energy, cable for flowing energy from the accumulator to the target, and cable for charging the accumulator, were used as signalized target points. They were affixed with chemical material to the lower surface of the bridge by using a maintenance support platform.

A 2-days image acquisition campaign was performed in the field. The imaging area of interest was set to $2352 \times 800$ pixels and the image acquisition frequency to $12 \mathrm{fps}$ in all three cameras. Each image frame is associated with a computer generated time tag, which consists of date, hour, minutes, seconds and milliseconds parts. 4800 three-fold image frames in the first day and 31968 three-fold image frames in the second day were acquired. A Matlab based photogrammetric software suit was specifically developed for this project.

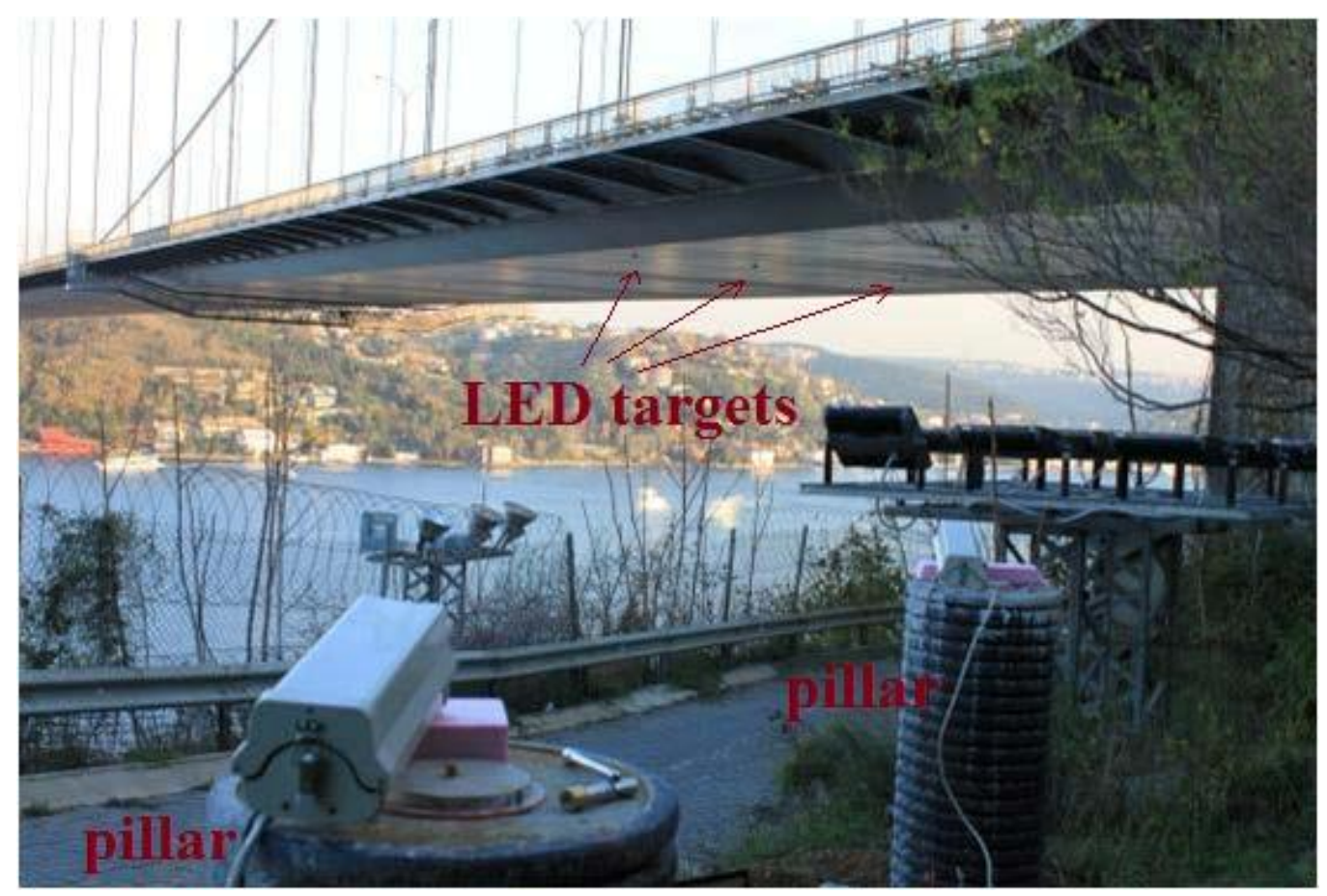

Figure 4. The two of the total four pillars 


\section{COMPUTATIONAL RESULTS}

The software can perform all the essential computational steps which are the image orientation, automatic target tracking and matching with cross-correlation, point positioning with selfcalibrating bundle adjustment, and visualization. The first day and the second day data sets were fully automatically measured in off-line mode. The average theoretical precision of the signalized points were computed as $\pm 72.4 \mathrm{~mm}, \pm 19.9 \mathrm{~mm}$, and $\pm 13.4 \mathrm{~mm}$ for the $\mathrm{X}, \mathrm{Y}$, and $\mathrm{Z}$ axes, respectively. The image assisted total station observations were used to validate the photogrammetric measurements. The horizontal displacements of the two representative targets are given in Figure 5.

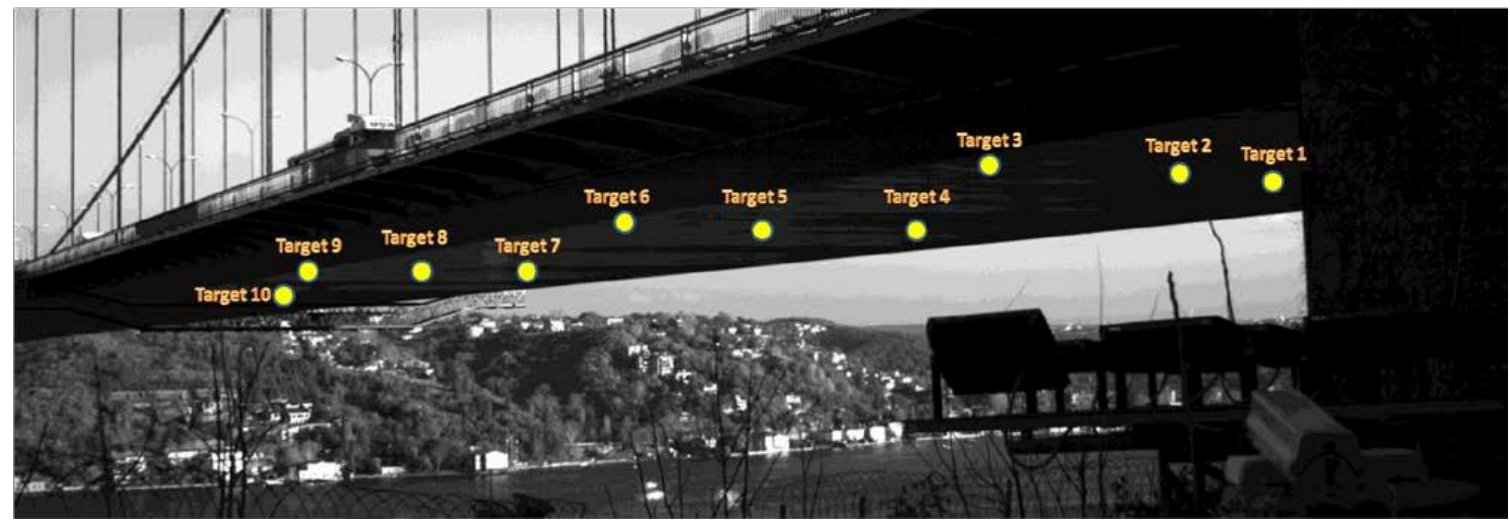

(a)
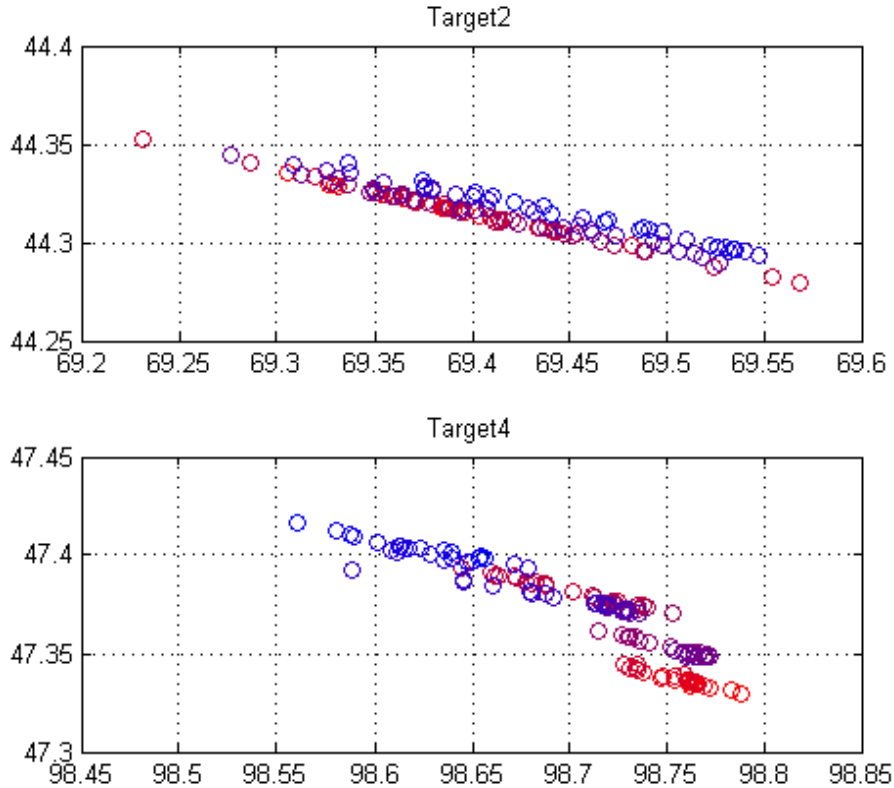

(b)

Figure 5. (a) Location of the 10 LED targets under the bridge surface. (b) The total displacement of Target 2 and 4.

CONCLUSION

Second Bosphorus Bridge is one of the main transportation routes in between Asia and Europe. Due to its importance, it is necessary to monitor this bridge, periodically. In this study, three still video cameras were used to monitor the movement of the bridge platform. From three imaging stations the first 150 meters of the bridge body was monitored using the photogrammetric technique with a $2352 \times 800$ pixels field of view and $12 \mathrm{fps}$ image acquisition frequency. A Matlab based photogrammetric software suit was specifically developed for image acquisition and photogrammetric evaluation (orientation, matching, positioning and visualization).

In the future work, further analysis steps will be performed by inspecting transportation load and weather (wind and temperature) conditions. This pilot project is going to be extended to monitor the entire bridge with an on-line photogrammetric monitoring and evalution system.

\section{REFERENCES}

Akca, D., Gruen, A., 2009. Comparative geometric and radiometric evaluation of mobile phone and still video cameras. The Photogrammetric Record, 24 (127), 217-245.

Akca, D., 2013. Photogrammetric monitoring of an artificiallygenerated shallow landslide. The Photogrammetric Record, 28(142), 178-195. 
Akyılmaz O., Çelik R. N., Apaydın N., Ayan T., 2004. GPS Monitoring of the Fatih Sultan Mehmet Suspension Bridge by Using Assessment Methods of Neural Networks, The International Archives of the Photogrammetry, Remote Sensing and Spatial Information Sciences, Istanbul, Turkey XXXV. Part B7, pp. 702-707.

Amiri Parian, J., Gruen, A. and Cozzani, A., 2007. Monitoring of the reflectors of ESA's Planck telescope by close-range photogrammetry. Journal of Applied Geodesy, 1(3): 137-145.

Apaydın N., 2002. Seismic Analysis of Fatih Sultan Mehmet Suspension Bridge, Ph.D. Thesis, Department of Civil Engineering, Boğaziçi University, Istanbul, Turkey

Apaydın N., Erdik M., 2001. Structural Vibration Monitoring System for the Bosporus Suspension Bridges, Strong Motion Instrumentation for Civil Engineering Structures, Kluwer Academic Publishers, pp. 343-367.

Bales F.B., Hilton M.H., 1985. Application of Close-range Terrestrial Photogrammetry to Bridge Structures, Virginia Highway and Transportation Research Council, USA.

Jauregui D.V., White K.R., Woodward C.B., Leitch K.R., 2003. Noncontact photogrammetric measurement of vertical bridge deflection, Journal of Bridge Engineering 8 (4), pp. 212-222.

Kim B.G., 1989. Development of a photogrammetric system for monitoring structural deformations of the sturgeon bay bridge, $\mathrm{PhD}$ Dissertation, University of Wisconsin, Madison, USA.

Koo KY, Brownjohn JMW, List D, Cole R, Wood T., 2010. Innovative structural health monitoring for Tamar Suspension Bridge by automated Total Positioning System, Bridge Maintenance, Safety, Management and Life-Cycle Optimization - Proceedings of the 5th International Conference on Bridge Maintenance, Safety and Management, pp. 556-563.

Koo KY, Brownjohn JMW, List DI, Cole R., 2013. Structural health monitoring of the Tamar suspension bridge, Structural Control and Health Monitoring, volume 20, no. 4, pp. 609-625.

Leitch K.R., 2002. Close-range photogrammetric measurement of bridge deformations. Ph.D. Dissertation, Civil and Geological Engineering Department, New Mexico State University, Las Cruces, New Mexico, USA.

Remondino F., 2004, 3-D Reconstruction of Static Human Body Shape from Image Sequence, Computer Vision and Image Understanding 93, pp. 65-85.

Zogg, H.-M., Ingensand H., 2008. Terrestrial Laser Scanning For Deformation Monitorıng - Load Tests on The Felsenau Viaduct $(\mathrm{CH})$, The International Archives of the Photogrammetry, Remote Sensing and Spatial Information Sciences, Beijing, China Vol. XXXVII. Part B5 pp. 555-561. 